\title{
Medical Care Satisfaction among Software Engineers in Bengaluru, Karnataka, India
}

\author{
${ }^{1}$ Srividya Venkatakrishna, ${ }^{2}$ Hrushikesh Udupa
}

\begin{abstract}
Background: Healthcare in India has seen many changes over the years. The objectives of healthcare changed with the requirements of society and the availability of resources and technology, even though the roles of patients and doctors have remained fixed. There is increased dissatisfaction among the public. It is vital to know exactly what our patients expect of us as their health care providers to practice according to the need of the day; in addition to ethically correct medicine. Bengaluru is known as IT capital of India with most of them being software engineers who often are first among the patients to be aware and informed of the diseases suffered by them or beloved ones. Hence, this study was undertaken with an objective of estimating the satisfaction of the medical care received by software engineers working in multinational companies in Bengaluru, Karnataka, India.
\end{abstract}

Methodology: The required number of engineers were selected using the snowballing technique until the sample size was met. The participants were given self-administered questionnaire (PSQ-18) after obtaining the consent. The selfadministered questionnaire consisted of demographic profile and 18 questions related to the medical system which were scored from agreeing to disagree strongly. The scoring was done using the scoring method for the PSQ-18 and overall satisfaction with the healthcare found along with subscores. Data were analyzed using SPSS 20 and chi-square was used as a test of significance.

Results: Mean age of the study population was found to be 26.4 years \pm 4 , with males representing the majority $(73.5 \%)$ of the study population. Overall satisfaction among engineers was found to be $55.5 \%$. Less satisfaction among participants was found when it came in terms of financial aspect $(28.5 \%)$ and time spent with doctors (31.5\%) followed by accessibility to health services (43\%).

Conclusion: A comprehensive approach involving all the stakeholders so as to arrive at a way to decrease the financial burden of the diseases as well as to improve time spent with the doctor is required.

Keywords: Medical care, Satisfaction, Software engineers

How to cite this article: Venkatakrishna S, Udupa H. Medical Care Satisfaction among Software Engineers in Bengaluru, Karnataka, India. Int J Med Sci 2018;4(3):71-74.

\footnotetext{
${ }^{1}$ Associate Professor, ${ }^{2}$ Postgraduate Student

1,2Department of Community Medicine, RajaRajeswari Medical College and Hospital, Bengaluru, Karnataka, India
}

Corresponding Author: Hrushikesh Udupa, Postgraduate Student, Department of Community Medicine, RajaRajeswari Medical College and Hospital, Bengaluru, Karnataka, India. e-mail: rkudupa@gmail.com

\section{Source of support: Nil}

Conflict of interest: None

\section{BACKGROUND}

Healthcare in India has seen many changes over the years. The objectives of healthcare changed with the requirements of society and the availability of resources and technology, even though the roles of patients and doctors have remained fixed. ${ }^{1,2}$ There have been many allegations about the medical care being too moneyminded and non-patient centric in the recent years. There is increased dissatisfaction among the public. Consumer/ patient satisfaction is recognized as an important parameter for assessing the quality of patient care services. ${ }^{3}$

Patient satisfaction has been defined as the degree of congruency between a patient's expectations of ideal care and his/her perception of the real care(s) he/she receives. It is a multidimensional aspect, represents a vital key marker of the quality of healthcare delivery, and this is an internationally accepted factor which needs to be studied repeatedly for the smooth functioning of the healthcare system. ${ }^{4}$

Studies have been conducted to assess the quality of services rendered by hospitals. These studies have been carried out, starting in Primary Health Centres to tertiary care centers, public and private hospitals. ${ }^{1,3-5}$ All these services measured the quality of the healthcare received by patients by measuring the satisfaction of the patients to the services received by them. The patient's satisfaction was assessed either in outpatients or inpatients while getting discharged. The questions were based on their experience at that particular hospital regarding their services ranging from registration in the hospital to the discharge. Such studies are helpful in knowing and improving the hospital, the study was carried out in. However, these studies cannot assess the overall satisfaction of the people towards the medical care received by them in the recent past. There are few such studies to assess the overall satisfaction hence the trust towards the healthcare system. Today, the patients are much more aware and informed about their diseases compared to most healthcare givers. It is, therefore, vital to know exactly what our patients expect of us as their healthcare providers in order to practice according to the need of the day; in addition to ethically correct medicine. ${ }^{2}$ Bengaluru is known as IT capital of India with most of 
them being software engineers who often are first among the patients to be aware and informed of the diseases suffered by them or beloved ones. Hence, this study was undertaken with an objective of estimating the satisfaction of the medical care received by software Engineers working in multinational companies in Bengaluru.

\section{MATERIALS AND METHODS}

An observational cross-sectional study was carried out from November 2015 to December 2015 in Bengaluru, among selected engineers working in multinational companies. Based on the pilot study the satisfaction regarding medical care was found to be $50 \%$. Considering this with $15 \%$ relative precision and $10 \%$ non-response rate the minimum sample size is 196 which was rounded off to 200. Engineers who were permanent residents of Bengaluru and working in the multinational company willing to participate were considered for the study

\section{Methods of Data Collection}

The required number of engineers were selected using the snowballing technique until the sample size was met. The participants were given self-administered questionnaire (PSQ-18) ${ }^{6}$ after obtaining the consent. The selfadministered questionnaire consisted of demographic profile and 18 questions related to the medical system which were scored from agreeing to disagree strongly. The scoring was done using the scoring method for the PSQ-18 and overall satisfaction with the healthcare found along with subscores

\section{Data Analysis}

The data collected was compiled in MS Excel sheet and analyzed using SPSS version 20. Qualitative variables were expressed as frequency and percentages. Categorical data was analyzed using chi-square test

\section{RESULTS}

Mean age of the study population was found to be 26.4 years \pm 4 , with males representing majority $(73.5 \%)$ of the study population (Fig. 1) All the participants were found to avail services from private sector. Overall satisfaction among engineers was found to be $55.5 \%$ (Fig. 2). Satisfaction in subscores were, technical quality (54.5\%), interpersonal manner $(49.5 \%)$, general satisfaction (48.0\%) and communication; (48.0\%). However less satisfaction among participants were found when it came in terms of financial aspect (28.5\%) and time spent with doctors (31.5\%) followed by accessibility to health services (43\%) (Fig. 3). Overall satisfaction

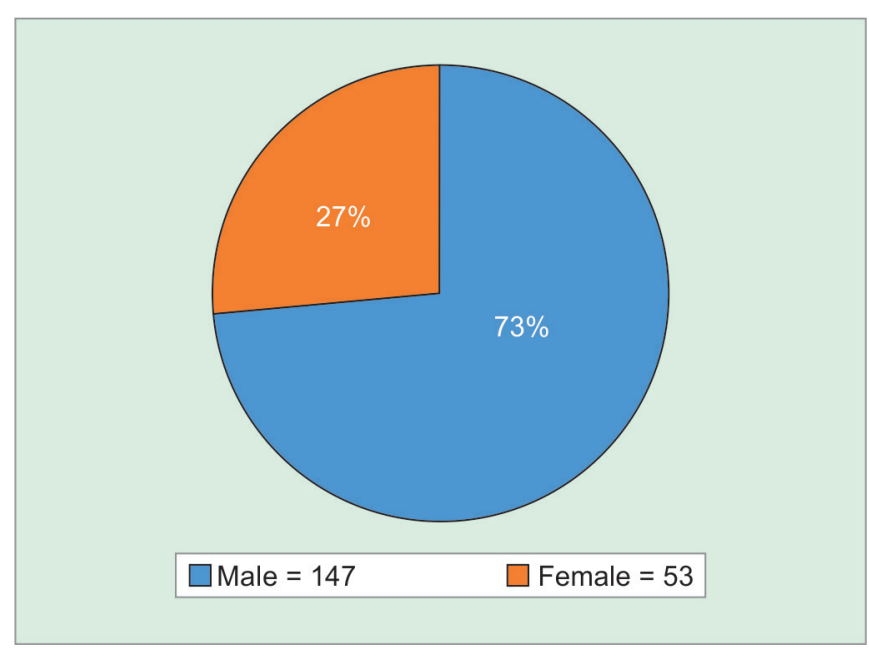

Fig. 1: Participants distribution based on gender $(N=200)$

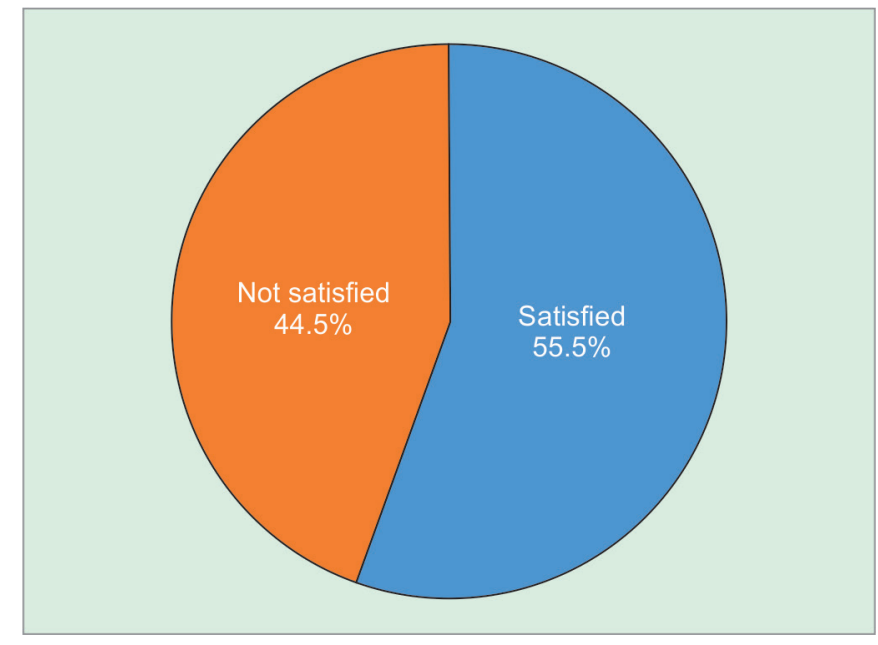

Fig. 2: Satisfaction regarding medical care received by participants $(N=200)$

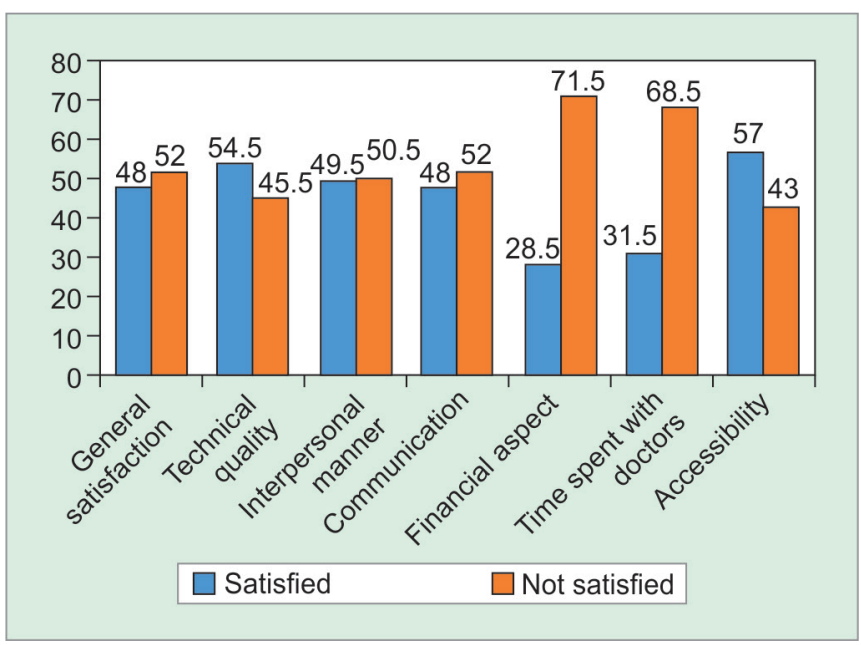

Fig. 3: Satisfaction among participants based on sub scores (\%)

regarding medical care was less among males (53\%) compared to females $(62.3 \%)$. The males were less satisfied compared to females in terms of communication, financial aspect, accessibility and time spent with 
Medical Care Satisfaction among Software Engineers

Table 1: Satisfaction among the study participants based on the gender along with the sub score

\begin{tabular}{|c|c|c|c|c|c|}
\hline & Gender & $\begin{array}{l}\text { Satsified } \\
(\%)\end{array}$ & $\begin{array}{l}\text { Not satisfied } \\
\text { (\%) }\end{array}$ & Total & $\begin{array}{l}\text { Chi-square and } \\
\text { p-value }\end{array}$ \\
\hline \multirow[t]{2}{*}{ Overall } & Male & $78(53)$ & $69(47)$ & 147 & \multirow{2}{*}{$\begin{array}{l}1.336 \\
0.24774\end{array}$} \\
\hline & Female & $33(62.3)$ & $20(37.7)$ & 53 & \\
\hline \multicolumn{6}{|l|}{ Subscores } \\
\hline \multirow[t]{2}{*}{ General satisfaction } & Male & $66(44.9)$ & $81(55.1)$ & 147 & 2.13 \\
\hline & Female & $30(56.6)$ & $23(43.4)$ & 53 & 0.14 \\
\hline \multirow[t]{2}{*}{ Technical quality } & Male & $79(53.7)$ & $68(46.3)$ & 147 & 0.12 \\
\hline & Female & $30(56.6)$ & $23(43.4)$ & 53 & 0.71 \\
\hline \multirow[t]{2}{*}{ Interpersonal manner } & Male & $73(49.7)$ & $74(50.3)$ & 147 & 0.006 \\
\hline & Female & $26(49.1)$ & $27(50.9)$ & 53 & 0.93 \\
\hline \multirow[t]{2}{*}{ Communication } & Male & $66(44.9)$ & $81(55.1)$ & 147 & 2.13 \\
\hline & Female & $30(56.6)$ & $23(43.4)$ & 53 & 0.14 \\
\hline \multirow[t]{2}{*}{ Financial aspect } & Male & $35(23.8)$ & $112(76.2)$ & 147 & \multirow{2}{*}{$\begin{array}{l}5.98 \\
0.014 \\
\text { Statistically } \\
\text { significant }\end{array}$} \\
\hline & Female & $22(41.5)$ & $31(58.5)$ & 53 & \\
\hline \multirow[t]{2}{*}{ Time spent with doctor } & Male & $42(28.6)$ & $105(71.4)$ & 147 & 2.20 \\
\hline & Female & $21(39.6)$ & $32(60.4)$ & 53 & 0.13 \\
\hline \multirow[t]{2}{*}{ Accessibility } & Male & $79(53.7)$ & $68(46.3)$ & 147 & 2.40 \\
\hline & Female & $35(66)$ & $18(34)$ & 53 & 0.12 \\
\hline
\end{tabular}

doctors (Table 1). This association between financial aspect and gender was found to be statistically significant $(p=0.014)$

\section{DISCUSSION}

This study was undertaken with an objective of estimating the satisfaction of the medical care received by software engineers working in multinational companies in Bengaluru. Mean age of the study population was found to be 26.4 years \pm 4 , with males representing the majority $(73.5 \%)$ of the study population. This was similar to studies done by Kausar et al. were males were more compared to females. ${ }^{3}$ All the participants were found to avail services from the private sector. Holikatti et al. ${ }^{7}$ and Ashraf et al. ${ }^{8}$ found overall satisfaction of patients to be 57 and $61 \%$ respectively similar to the findings in this study (55.5\%). However, increased satisfaction was found in the study done by Qadri et al. ${ }^{4}$ where the overall satisfaction was found to be $79.3 \%$. Less satisfaction in the subscores among participants was found in terms of financial aspect (28.5\%) and time spent with doctors $(31.5 \%)$ followed by accessibility to health services (43\%) similar to study done by Sivalenka, ${ }^{9}$ where significant dissatisfaction was observed among financial aspect. Overall satisfaction regarding medical care was less among males $(53 \%)$ compared to females $(62.3 \%)$ in contrast to study done by Mohamed et al. where males $(84.3 \%)$ were more satisfied compared to females(79.8\%) The males were less satisfied compared to females in terms of communication, financial aspect, accessibility and time spent with doctors. This association between the financial aspect and gender was found to be statistically significant $(p=0.014)$; however, no statistical significance was seen in the study conducted by Holikatti et al. ${ }^{7}$

\section{CONCLUSION}

It was observed that most of the software engineers were satisfied with the medical care received, however, less satisfaction was found among the study participants when it came in terms of financial aspect and time spent with doctors. Males were less satisfied regarding financial aspects compared to females and this difference was found to be statistically significant.

\section{REFERENCES}

1. Raghunath E, Vijayalakshmi S, Sathagurunath PA. A Study of outpatient satisfaction at primary health centers in Puducherry. Health. 2013;1(4):118-121 available from: https://www.academia.edu/7345574/A-study-of-outpatientsatisfaction-at-primary-health-centers-in-Puducherry ${ }^{2}$ last accessed 18 Nov 2015

2. Khattak A, Alvi MI, Yousaf MA, Shah SZA, Turial D, Sohail Akhter. Patient Satisfaction - A comparision between public and private Hospitals of Peshwar. International J collaborative Research on Internal Medicine and Public Health. 2012;4(5): 713-722 available from https://www.researchgate.net/publication/268435751_Patient_Satisfaction_-_A_Comparison_ 
between_Public_Private_Hospitals_of_Peshawar last accessed 20 Nov 2015.

3. Kausar H, Shafee M, Gangwal PR Assessment of satisfaction among OPD patients at Noor hospital,Warudi, Badnapur. MRIMS J health Sciences 2015;3(1):42-44 available from http://www.mrimsjournal.com/journal/uploads/ c1434697507MRIMSJHS_Article_11.pdf last accessed 20th Nov 2015.

4. Qadri SS, Pathak R, Singh M, Ahluwaha AK, Saini S, Gary PK. An assessment of patients satisfaction with services obtained from tertiary care hospital in rural haryana. Interesting J collaboration Res Internet med public health 2012;4:1524-1537 available from www.iomcworld.com/ijcrimph/files/v04-n0804.pdf last accessed on 10th Nov 2015.

5. Mohamed EY, Sami W, Alotaibi A, Alfarag A, Almutairi A, Alanzi F. Patients' Satisfaction with Primary Health Care Centers' Services, Majmaah, Kingdom of Saudi of Saudi Arabia. Int J Health Sci (Qassim). 2015 Apr;9(2) 163-170. available from https://europepmc.org/articles/ PMC4538893 last accessed on 10th Nov 2015.
6. Patient Satisfaction Questionnaire from RAND Health [Internet]. Rand.org. Available from: https://www.rand.org/ health/surveys_tools/psq.html last accessed on 14th nov 2015.

7. Holikatti PC, Kar N, Mishra A, Shukla R, Swain SP, Kar S. A study on patient satisfaction with psychiatric services. Indian Journal of Psychiatry. 2012; 54(4):327-32 available from http:// www.indianjpsychiatry.org/downloadpdf.asp?issn=00195545 ; year $=2012$; volume $=54 ;$ issue $=4$; spage $=327$; epage $=332$; aulast $=$ Holikatti;type $=2$ last accessed on 14 Nov 2015.

8. Ashraf M, Ashraf F, Rahman A, Khan R. Assessing women's satisfaction level with maternity services: Evidences from Pakistan.International Journal of collaborative research on Internal Medicine and Public Health. 2012;4(11):18411851 Available from http://hdrfoundation.org/docs/ articles/assessing-womens-satifaction-level-with-maternityservices-evidence-from-pakistan.pdf last accessed on 20th Nov 2015.

9. Sivalenka S. Patient Satisfaction Surveys in Public Hospitals in India. Available from: http://www.rand.org. last accessed on 20th Nov 2015. 